\title{
Presencia de la mujer en la asistencia social en México
}

Gloria Guadarrama Sánchez El Colegio Mexiquense

\section{Introducción}

La asistencia social es una de las opciones a las que la sociedad mexicana ha dado cierta vigencia para enfrentar la pobreza; no obstante, a lo largo de casi siglo y medio, la asistencia como política pública y como acción de grupos privados ha ido percibiéndose como un sistema de múltiples propósitos, cursos diversos y destino incierto, más que como un solo camino directo y ascendente, próximo a arribar a la meta de abatir la pobreza. Los cambios en las formas que han asumido las políticas asistenciales en un momento o ciclo determinado se estiman influidos por otros procesos más o menos visibles en el espectro más amplio del desarrollo nacional, las esferas del Estado, la política, la cultura y la sociedad, y asociados a nociones más generales e integradoras de significados sociales; destacan entre estas últimas las nociones de lo público y lo privado. El propósito de este artículo es explorar la reconfiguración de las políticas asistenciales como un proceso relacionado con la reconstitución de las nociones de lo público y lo privado; destacando en estos vínculos la participación de la mujer en la asistencia social mexicana. Para este objeto se aborda someramente el proceso de formación de las políticas públicas de asistencia social; se revisan algunos aspectos conceptuales de la reconstitución de los ámbitos público y privado; se examinan algunas de las formas que ha asumido la participación de la mujer en el terreno asistencial; se establecen referencias entre estos pro-

Economía, Sociedad y Territorio, vol. II, núm. 5, 1999, 117-147. 
cesos y las políticas asistenciales, con la intención de concretar y dar rostro al papel que ha desempeñado la mujer en los procesos de reconfiguración y cambio de la asistencia social mexicana, y se aportan elementos para reconocer la importancia de su participación como actor social de la asistencia.

\section{La sociedad y la asistencia social}

A punto de dar el paso que las llevará al tercer milenio, las sociedades contemporáneas presentan un panorama contrastante y diverso: frente al progreso de los países más desarrollados, aparecen la miseria, el atraso y aun la muerte diaria de miles de seres humanos por razones de desigualdad y desequilibrios en el desarrollo. Ante estos problemas se destaca también la presencia de una conciencia cada vez más generalizada de que la colectividad no puede abandonar a sus miembros más débiles y que la solución a los problemas de la pobreza requiere de la participación de todos; conciencia que impulsa la realización de acciones de asistencia social tanto en la esfera del Estado como en la de la sociedad civil. La asistencia se sustenta en el reconocimiento de otras personas como seres humanos, hombres y mujeres que son como nosotros y por ello pueden tener derecho a ser asistidos en situación de necesidad (Rawls, 1971; y Walzer, 1983). Obligación moral que se genera bajo el principio de asistencia mutua, que resume una de las formas de interrelación entre los individuos.

La asistencia como responsabilidad del Estado y del cuerpo social tiene raíces en tradiciones morales vinculadas con la caridad y la beneficencia, emergiendo en su sentido moderno asociada al pensamiento de la Ilustración, que durante los siglos XVIII y XIX, generó nuevas formas de organización de la vida pública y social, formas que estuvieron estrechamente ligadas a la aceptación generalizada de los derechos individuales y del papel del Estado como salvaguarda del bienestar general de la sociedad (Kusnir, 1996; Cohen y Arato, 1996; Sievers, 1995; y Padilla, 1995). ${ }^{1}$

La génesis del pensamiento sobre el Estado moderno se encuentra estrechamente ligada a las ideas que lo distinguen de

${ }^{1}$ Aun cuando los autores que se mencionan no se ocupan específicamente de la asistencia: Kusnir (1996) remite al final del siglo XIX la etapa pionera de la política social y las acciones que considera son de naturaleza asistencial. Padilla (1995) señala al pensamiento ilustrado como el que gestó una nueva concepción del tema de la pobreza 
la sociedad civil y a las percepciones de los ámbitos público y privado como esferas separadas, separación sustentada inicialmente en la necesidad de fijar límites a la intervención del Estado, abrir espacios para la discusión pública y, sobre todo, en la secularización y diferenciación entre la Iglesia y el Estado (Seligman, 1996). Estos procesos marcan el tránsito de una sociedad global hacia una sociedad diferenciada y permiten la configuración de distinciones entre la esfera pública (estatal) y la privada (religiosa, social), así como apuntar tanto la responsabilidad del Estado ante las necesidades de la pobreza, como la del individuo, a quien se considera portador de derechos y agente de la conciencia moral.

Interesa aquí dejar asentado que la preocupación de la sociedad por el bienestar colectivo y la gradual aceptación del bien común como una responsabilidad de todos, fueron determinantes para asumir la pobreza como una problemática social más que individual, modificándose las formas tradicionales de atención a los pobres centradas en la caridad y la beneficencia, organizadas generalmente en torno a la esfera religiosa. Las nuevas formas de encarar las necesidades sociales se reflejaron tanto en la necesidad de una política social, como en la toma de conciencia pública que dejó de ver la miseria como un hecho natural: producto de situaciones de abandono, falta de disciplina, irresponsabilidad, resultado del vicio, la escasa dignidad y autoestima; dando paso a considerarla como uno de los efectos del sistema económico y/o de la organización social. ${ }^{2}$

El paso decisivo de esta transformación estriba en que la sociedad dejó de ver la erradicación de la pobreza como una aspiración ética deseable, producto de la conciencia y la moralidad individual, pero secundaria al ejercicio de la libertad personal; pasando, mediante la cesión de algunas libertades individuales en favor del Estado, a aceptar que éste fuese la instancia promotora

y de los pobres. Cohen y Arato (1996) ubican en la Ilustración la diferenciación entre gobierno y sociedad y le dan el carácter de prototipo de las acciones de la moderna sociedad civil, entre ellas la filantropía. Sievers (1995) enfatiza la centralidad de los derechos individuales, el sentido de propósito común y la responsabilidad cívica, que forman parte del liberalismo de la Ilustración, como importantes en la diferenciación entre sociedad y Estado y en una visión moderna de la vida que incluye a la filantropía.

${ }^{2}$ Numerosos estudios refieren cómo las funciones asistenciales en Europa occidental eran confiadas a las corporaciones de artes y oficios y sociedades de ayuda mutua, explicando la forma como la previsión social se impuso ante los riesgos de la pobreza, surgidos como consecuencia de la revolución industrial, dando lugar al nacimiento de las ideas que sustentaron al Estado de Bienestar que caracterizó a algunos países europeos durante la primera mitad del siglo xx (Kusnir, 1996). 
y responsable de asegurar un cuerpo de derechos inalienables del ser humano. Así, el sentido de responsabilidad social, los valores, los derechos individuales y la obligación cívica, que fortalecen la participación de la sociedad civil, fueron factores determinantes para la conformación de los conceptos modernos del Estado y de la asistencia social.

\section{La relación público-privado en la asistencia social}

Uno de los aspectos relevantes en la diferenciación entre el Estado y la sociedad civil, así como en la concepción misma de la asistencia, es su vinculación con las nociones de lo público y de lo privado. Lo público y lo privado son conceptos básicos que estructuran y dan coherencia a la vida social, tejiendo una orientación o intersubjetividad compartida, la cual sustenta cierta normatividad, criterios de valor y límites, que articulan y dan sentido a la acción humana (Elshtain, 1981). Por esto mismo, son conceptos que contienen elementos de movimiento y modificación permanentes, además de múltiples significados y dimensiones, que tienen que ver con contextos coyunturales y circunstancias temporales, más que con rasgos estructurales que pudieran establecer distinciones únicas. ${ }^{3}$

La diferenciación entre lo personal, familiar, doméstico; ${ }^{4}$ lo visible y lo inherente a la sociedad en general; así como lo referido al Estado y lo que se considera de interés general, apunta a una red de interrelaciones y diferencias que conforman esferas interactuantes entre los planos diversos y cambiantes que constituyen el universo de lo social, encontrándose en constante redefinición. El carácter móvil y abstracto de estos conceptos -que entre otros, son parte constitutiva de las esferas de lo público y lo privado- les confiere una imprecisión que sólo puede anclarse en las particularidades de la realidad social. Uno de los propósitos de este escrito es anudar estas reflexiones en las políticas

${ }^{3}$ De acuerdo con Koselleck, muchos conceptos políticos modernos incluyen un coeficiente de modificación que progresa con el tiempo y que en rigor convierte el concepto en una anticipación (Koselleck, 1993).

4 Es frecuente que estos términos sean utilizados en forma indistinta; no obstante, tienen conceptos y significados diferentes y cambiantes; así por ejemplo, lo personal se vincula más con lo individual, lo doméstico refiere a representaciones del hogar y su funcionamiento, mientras que lo familiar incluye en su significación contenidos de relaciones interpersonales, sexuales y de interdependencia. 
asistenciales y en la participación de las mujeres en la asistencia destacando los vínculos que existen entre ellos.

A efecto de revisar los procesos de reconfiguración de estos ámbitos en la asistencia social, cabe recordar aquí que las distinciones entre la sociedad civil y el Estado, al principio de la modernidad, marcaron también la separación entre lo público y lo privado, orientando el pensamiento de lo público como lo perteneciente a la esfera estatal, y lo privado como lo referido a la sociedad en general; siendo esta última una esfera que integraba las libertades que esa sociedad podía ejercer sin la interferencia del Estado, opuesta en cierta medida, a su poder absoluto (Cohen y Arato, 1996; Habermas 1989; y Kymlicka, 1990). Esta distinción inicial fue transformándose en la medida en que cambiaron las relaciones entre la sociedad y el Estado y se modificaron los ámbitos de lo individual, lo familiar y lo social. En las sociedades contemporáneas existen nuevas y diversas distinciones entre estos ámbitos que determinan las esferas de lo que se considera público, privado y social.

En la tradición liberal individualista, lo público como lo opuesto a lo privado es aquello que no tiene una relación inmediata con alguna persona o grupo específico, pero que puede ser, sin distinción alguna, directamente concerniente al interés de cualquiera de los miembros de una comunidad. ${ }^{5}$ La responsabilidad del Estado por promover el bien común, define el carácter de la asistencia como política pública. La actuación pública en lo asistencial implica, como en otros terrenos afines, la imparcialidad en la consideración de los intereses de cada persona, ya que cuando se actúa privadamente, está implícita la libertad de perseguir los fines propios o de unirse a otros para lograr fines compartidos (Rawls, 1995; y Kymlicka, 1990). En este contexto, lo público puede establecer su referencia con los asuntos del Estado y con la estrecha vinculación que históricamente ha tenido con el interés común y con la búsqueda de mayor bienestar. ${ }^{6}$

${ }^{5}$ Esta forma de concebir lo privado y lo público sigue las reflexiones de Benn y Gaus que destacan los vínculos de la concepción liberal con los principios del individualismo, y consideran que resume los varios niveles en los que las distinciones entre lo público y lo privado pueden ser efectuadas (Benn y Gaus, 1983:32).

${ }^{6}$ Oszlak advierte sobre la posición un tanto ingenua de ver en las políticas públicas la expresión del interés general de la sociedad y del consenso, sin dejar de lado las razones que sustentan el hecho de percibirlas como la arena en la que se dirimen las posiciones en conflicto de los actores sociales, resulta necesario partir de las ideas explícitas en las cuales se sustenta la concepción de lo público (Oszlak, 1980). 
En el terreno de la asistencia, distinguir lo público de lo privado tuvo que ver, primero, con la transformación de las formas tradicionales de ejercer y practicar la caridad y con asumir la atención a la pobreza como una responsabilidad colectiva; asimismo, se asoció con las aspiraciones de equidad que buscaban asegurar bienestar y progreso para todos, diferenciando las acciones que debía realizar el Estado con esos propósitos, de las que eran emprendidas por individuos y grupos por razones religiosas, altruistas o compasivas. Estas últimas se consideraban privadas, no solamente por ser ejercidas como prerrogativas derivadas de las libertades individuales, sino también porque se desarrollaban muchas veces vinculadas con la extensión de los deberes familiares y religiosos con la discreción, intimidad y decoro que priva en el ámbito doméstico.

Aplicando al rubro asistencial las reflexiones de Rawls sobre la razón pública, se podría pensar que la aceptación de principios y formas para enfrentar la pobreza en las diversas sociedades, se concreta en concepciones políticas sobre la intervención del Estado en materia de bienestar y derechos sociales. La percepción de que es correcto y adecuado que el Estado asista a los débiles y vulnerables y a los pobres, posibilita hacer a un lado diferencias de orden religioso, filosófico o moral, constituyendo la base para la configuración de las políticas asistenciales; apuntando además hacia la delimitación del ámbito que es posible identificar como asistencia pública: ${ }^{7}$ "La razón pública condensa el acuerdo de los ciudadanos en torno a principios esenciales y básicos de justicia, traducido en forma de concepciones políticas, cuyos principios podrían ser suscritos por todos los ciudadanos" (Rawls, 1995:35). ${ }^{8}$

De acuerdo con Seligman, la diferenciación entre lo privado y lo público se fortaleció cuando la moralidad se consideró inherente al hombre, deslindándola de sus vínculos teológicos; entonces la distinción entre lo privado y lo público adquirió rele-

${ }^{7}$ Es necesario tener presente que la posición de Rawls refiere a la justicia como principio primario, por lo que desde su punto de vista, “[...] la razón pública puede ser pública de tres maneras: como la razón de los ciudadanos como tales, es la razón de lo público, su sujeto es el bien del público y sus asuntos son los de la justicia fundamental, y su naturaleza y contenido son públicos, dados por los principios e ideales que expresa la concepción de la sociedad acerca de la justicia política, y conducidos a la vista de todos sobre esta base." (Rawls, 1995:35). Las cursivas son del autor.

${ }^{8}$ Si bien las tesis de Rawls han sido objeto de crítica por parte de los teóricos comunitaristas, aquí interesa destacar los vínculos del consenso con la noción de lo público como competencia de las políticas públicas estatales. 
vancia, concibiéndose en términos de las bases morales del orden social. Esto tuvo también que ver con la distinción entre la ley y la virtud; es decir, entre los derechos jurídicos que regían la esfera pública y una esfera más individual o privada de moralidad o virtud (Seligman, 1996:30).

Estas esferas se reconstituyeron nuevamente en la medida en que lo público fue percibido también como el campo de interacción de la sociedad civil, o como el terreno en el que individuos y grupos podían participar en el debate y crítica de los asuntos públicos. Se puede decir que en los últimos cien años, la distinción original entre lo público y lo privado fue suplida por una segunda distinción en la que se separa lo personal o íntimo, de lo público; y lo público incluye simultáneamente lo estatal y lo social (Kymlicka, 1990:257). De este modo, la noción de lo público fue reconfigurada en una esfera intermedia de interés general en la que confluyen el Estado y la sociedad.

La extensión de lo público y de lo privado al terreno social trajo consigo nuevas reformulaciones en el rubro asistencial, perdiéndose las separaciones tajantes entre la asistencia pública y la privada, y conformándose lo social como un espacio intermedio en el que individuos y grupos privados podían participar públicamente en la asistencia, asumiendo mayores responsabilidades en la solución de los problemas sociales, lo que se acompañó del cuestionamiento de las formas asistenciales y de la capacidad del Estado como sintetizador de la acción social y para enfrentar los problemas de la pobreza.

La interacción de las formas en que se articula hoy día la vida social ha transformado la vida doméstica y las relaciones familiares; existe actualmente una mayor participación de la mujer y se han dado cambios significativos en el papel del trabajo en las sociedades humanas, cambios que han activado la redefinición de las esferas de lo público y de lo privado. La privacidad contemporánea es vista ya no como lo opuesto a la esfera política, sino como lo familiar, lo individual, lo íntimo, opuesto en muchos casos a lo social. En el ámbito asistencial lo privado significa ahora involucramiento activo con las instituciones de la sociedad civil que se preocupan por la pobreza. Es en ese sentido que la relación público-privado forma parte imprescindible de la concepción de la asistencia social, bien sea que se refiera a la responsabilidad estatal o a las acciones asistenciales en la esfera de la sociedad civil y aun a aquellas ejercidas individualmente. 


\section{Lo público, lo privado y la participación de las mujeres en la asistencia}

La asistencia social ha sido tradicionalmente uno de los espacios de participación femenina; la imagen de la mujer caritativa y benevolente, ocupada en socorrer a los pobres, o al cuidado de los desvalidos, forma parte de aquellas que tradicionalmente han tenido mayor aceptación y reconocimiento de los roles femeninos. Esta imagen se ha vinculado con la de la mujer en el ámbito privado, en oposición al mundo político o público. En la vinculación entre la esfera privada y la mujer, es necesario tener en cuenta que las determinaciones sobre lo que las sociedades consideran público o privado, condicionan actitudes hacia las mujeres; así por ejemplo, el pensamiento de lo privado como lo concerniente al universo familiar, restringió la actividad pública de la mujer.

La concepción liberal de lo privado como el ámbito amplio de no-interferencia del Estado y la indiferencia de la sociedad hacia la esfera doméstica, más que su inclusión en lo privado, ${ }^{9}$ acentuó en los inicios de la modernidad la tradicional confinación de la mujer en el hogar, afianzando el modelo de madreesposa, destinada a la maternidad y la procreación. Hasta bien entrado el siglo xx, en muchos países europeos y todavía hoy en algunos de los latinoamericanos, había sido de aceptación común que el matrimonio significara el alejamiento de la mujer de la vida pública y social; bajo la supuesta existencia de una vocación natural, asociada con el reconocimiento de la maternidad como función social femenina. Esta posición significó dejar el mundo público para los hombres y a las mujeres inmersas en el ámbito privado, entendido éste como lo no público y al margen del poder público, lo que de algún modo se tradujo en subordinación de las mujeres.

Desde finales del siglo XIX, las luchas de las mujeres por obtener derechos políticos y sociales, por la ciudadanía y por el

9 Algunos autores consideran que el espacio doméstico y los roles femeninos se construyeron bajo el modelo de una sociedad patriarcal, y que el hogar era considerado una extensión del pater familias, siendo estimado como ámbito de ejercicio de su propiedad (Benn y Gaus, 1983); las concepciones y reglas de libertad que se establecieron para la esfera privada, no fueron entonces extensivas al hogar, lo que generó, entre otros factores, las condiciones de inequidad y restrictividad que por siglos sufrieron las mujeres. Kymlicka (1990) opina que la distinción que prevalece entre lo público y lo privado, con la no-interferencia del Estado y de la sociedad en el hogar, ha sido determinante para que las mujeres todavía no ejerzan a plenitud sus derechos, y que sería necesaria una reconceptuación de estos ámbitos en las teorías sobre la justicia, y una apertura de lo doméstico hacia lo público, para cambiar la actual situación de inequidad. 
bienestar, estuvieron estrechamente unidas. La noción misma de bienestar, como mejoramiento de las condiciones de vida, está indisolublemente ligada a las condiciones de los hogares, a la salud, y a la alimentación de los hijos. Los movimientos reivindicadores de las mujeres se centraron fundamentalmente en las necesidades e intereses de las mujeres de las clases menos favorecidas y en la pobreza femenina, demandando políticas sociales que atenuaran sus deplorables condiciones. De este modo, iniciaron y dieron forma a una importante legislación social favorable sobre todo a la protección materno-infantil. Es decir que la liberación de las mujeres, la lucha por mayor bienestar y contra la pobreza, marcharon entrelazadas, estableciéndose una red de vínculos entre la participación de las mujeres, la creación de instituciones asistenciales y la concepción misma de la asistencia como acción pública o privada.

La percepción de las mujeres como seres libres e iguales abrió la posibilidad de su entrada en el ámbito público y se ha avanzado progresivamente en la obtención de igualdad de oportunidades de acceso a la educación, a la salud, al empleo y participación política. La mayor igualdad de la mujer, su significación como sujeto individual, y el ejercicio de sus derechos, incidieron también en la transformación del ámbito doméstico y familiar, cambiando del modelo dominante de madre-esposa, a una pluralidad de modelos femeninos. Asimismo, la liberación de las mujeres de las restricciones impuestas por el espacio doméstico -debida en buena medida a su afirmación en el mundo laboral, al reconocimiento a sus derechos políticos, así como a su presencia creciente en la cultura y la política-, interactuó con la transformación de las nociones de lo público y de lo privado, ampliando sus espacios de participación.

Aun cuando las distinciones entre lo público y lo privado no se corresponden estrictamente con una diferenciación sexual, porque no todo lo privado ha sido considerado femenino ni lo público exclusivamente masculino, la aceptación durante largo tiempo de estas distinciones tuvo entre sus efectos el que se pensara que los hombres y las mujeres desarrollan diferentes actitudes y modos de pensamiento ante la pobreza, vinculándose a las mujeres con una orientación hacia la protección y el cuidado de los desvalidos y a los hombres con una orientación más universal y abstracta hacia la justicia. La primera sería una derivación de actitudes de formación en el hogar y la segunda en el espacio público. 


\section{La mujer y la filantropía}

La emergencia y dimensiones de la pobreza acentuadas durante la fase expansiva del capitalismo y de la revolución industrial, a mediados del siglo XIX en Europa, y las nuevas ideas sobre el Estado y la sociedad civil, influyeron también en las formas como se ejerció la caridad privada. En este espacio las mujeres desempeñaron un papel significativo en la conformación de nuevos modelos para la beneficencia y la filantropía, que son el antecedente de las modernas asociaciones y organizaciones de la sociedad civil. Pareciera ser que la beneficencia privada en la época moderna, se desarrolla como un contrapunto y un referente obligado para la asistencia pública, constituyendo una considerable influencia en la configuración de los paradigmas asistenciales. Al respecto, algunos estudios refieren que las mujeres tuvieron en este ámbito un papel importante, porque la caridad con la que tradicionalmente se cumplía, como una parte de los deberes religiosos, se integró con otros procesos vinculados con la emancipación femenina y la emergencia de la identidad de la mujer como portadora de derechos. La mujer bajo el signo de una religiosidad práctico-caritativa, que se movía directamente en el campo de la extendida miseria social, unió a las prácticas de caridad las posibilidades de movimiento que le permitieron afirmar su identidad, su libertad espacial y su capacidad de acción social (De Giorgio, 1993; y Perrot, 1993).

En el mismo sentido, es posible advertir que en el aparente antagonismo entre la asistencia privada y la pública -que se mueve entre los espacios de la visión individualista y de la responsabilidad colectiva, de la secularización y la religiosidad, de lo privado y de lo público-, pudiera insertarse la acción filantrópica de las mujeres, como un puente de articulación entre lo moral y lo social, impulsado como una propuesta de valores alternativos y como el desarrollo de una conciencia de los deberes sociales, que es desarrollada por las mujeres frente a la gestión masculina del poder que las excluye de la escena política y social.

Este enfoque destaca la forma en la que la evolución económica significó también un cambio en las estructuras familiares y el modo en el que el auge industrial alejó a las fábricas del hogar familiar, materializando la separación entre las esferas del hogar y del trabajo y remitiendo a las mujeres a la vida doméstica. Se considera que esta separación impulsó la génesis de valores entre los que se exaltan los vinculados con la familia y la 
religión, y que fueron presentados como opuestos a los de los hombres y a los del mundo secular, del Estado y de la política. Por caridad cristiana, las damas de la burguesía y la aristocracia fundan guarderías infantiles, parvularios, patronatos, talleres; y exhortan a las mujeres del mundo entero a hacerse cargo de la situación material y moral de los más desposeídos, conformando una verdadera movilización femenina bajo el sello del deber social (Knibiebler, 1993:355; y Perrot, 1993:461-462).

\section{La mujer y la asistencia pública}

Pero no es solamente en el campo de la filantropía y la asistencia privada donde las mujeres hacen acto de presencia. Los programas sociales públicos también son considerados espacios propicios para que las mujeres que empiezan a integrarse al mundo laboral, desarrollen las tareas que por sus características se consideran una extensión del hogar, y en las cuales tienen cabida natural las virtudes consideradas femeninas: la sensibilidad, la bondad, la compasión y la solidaridad, constituyen rasgos valiosos para quienes esperan mitigar la pobreza.

La presencia creciente de las mujeres en el mercado de trabajo, así como en el campo de la cultura y la política, provocó la evolución del derecho privado, propiciando la ampliación de la esfera pública femenina. En esta forma, las mujeres también pudieron abrir espacios y modos de socialización propios, que algunos estudios consideran (Thebaud, 1993:20) que contribuyeron a desarrollar en ellas las cualidades necesarias para el trabajo de reproducción; rasgos que son comúnmente identificados con la noción de oficio y vocación femenina. Algunas tesis apuntan que el trabajo femenino traduce la emergencia de un régimen de reproducción post-industrial, cuya característica es la colectivización y la intelectualización del trabajo de reproducción, entendida como tipos de trabajo ligados a la socialización inicial o continua de la población (Lefaucheur, 1993:439-463).

Entre las repercusiones de este proceso estuvo el que las mujeres ampliaran su campo de intereses, pasando del interés por la beneficencia y las actividades filantrópicas, a la educación y los derechos políticos y sociales. La administración pública de la asistencia, desde sus inicios, refleja estos movimientos, dando cabida en sus niveles operativos (escasamente en los ejecutivos) a un buen número de mujeres que como enfermeras, maestras, ni- 
ñeras o madres sustitutas, engrosan las filas de los que se ocupan de atender a niños, ancianos, enfermos y a otras mujeres que por su condición, requieren tanto de apoyo a la satisfacción de sus necesidades esenciales, como de consejo moral.

En la perspectiva de este análisis, es indispensable tener presente cómo la amplitud de los problemas sociales del siglo XIX, y su progresión en el Xx, promueve, por una parte, la conformación de una política social vinculada con el mundo del trabajo, de la gestión pública y de los nuevos conceptos sobre el bienestar; y por la otra, convierte a la caridad en una exigencia y en un espacio en el que en la filantropía, las mujeres encuentran un camino para salir y pasar del sometimiento a los derechos sociales.

\section{Las mujeres en la asistencia social mexicana}

La ayuda a los pobres aparece históricamente como una preocupación constante de la sociedad mexicana. El principio de su integración como una responsabilidad pública se asocia con la consolidación del proyecto de Estado y de nación, en la segunda mitad del siglo XIX, cuando la asistencia pasa de ser una virtud asociada con la caridad religiosa y la filantropía, a constituirse en una tarea del Estado. El cambio está inserto en la conformación de los nuevos consensos axiológicos relacionados con el proceso de diferenciación y separación de la Iglesia y el Estado y con la distinción entre sociedad y organización religiosa, en consonancia con el tránsito de una sociedad global a una sociedad que confina lo religioso, lo político y lo económico a ámbitos y formas particulares de organización social; transformaciones que se acompañan de una diferenciación entre lo privado y lo público. ${ }^{10}$ Este proceso, plasmado en las Leyes de Reforma, se tradujo, gradualmente, en un fortalecimiento de las estructuras estatales y fue otorgando una fundamentación laica y humanista a las tareas asistenciales, que empiezan a verse así como una responsabilidad del cuerpo social.

${ }^{10}$ Luckmann asocia el proceso de secularización, distintivo del cambio de la religión en la época moderna, con el tránsito del universo religioso, de su integración en la esfera más global de la sociedad, hacia esferas separadas jurisdiccionalmente de lo religioso, lo social y lo político, y en su desplazamiento hacia la religiosidad individual y privada (Luckmann, 1973). 
La visión individualista del pensamiento liberal tendía a considerar un carácter pasivo del Estado ante la pobreza, con base en la idea generalizada, en ese momento, de que cada individuo era responsable de su situación personal. Por su parte, la visión de la responsabilidad social que empezaba a conformarse, surgía ante la necesidad de contar con instancias generadoras de coberturas sociales y con una concepción de la modernidad que, para la incipiente organización de la administración pública, se asociaba con asumir responsabilidades antes reservadas a la Iglesia. En ese contexto, algunas de las medidas de ayuda, asistencia y beneficencia, fueron asumidas por el Estado, aun cuando éste careciera de los recursos para enfrentar los problemas. ${ }^{11}$

En el devenir histórico del país fueron cambiando la disposición y las relaciones entre los actores de la asistencia social, y se conformaron nuevos consensos y disensos respecto a las responsabilidades del Estado, la Iglesia y la sociedad ante el bienestar; acuerdos y diferencias que fueron determinantes en los diversos momentos históricos en las formas y peculiaridades que asumieron la política asistencial pública y la asistencia privada.

No resulta aventurado pensar que a lo largo de este proceso las mujeres fueran uno de los actores principales de los programas de asistencia social, tanto en el ámbito público como en el privado. Al respecto, la historia da cuenta de la presencia e impulso que las mujeres daban a las actividades filantrópicas, de su papel destacado en el mantenimiento y conformación de organizaciones públicas y privadas de asistencia social, y del apoyo que por medio de grupos voluntarios han brindado a las tareas asistenciales. Resulta interesante considerar si esa presencia se vincula con los roles que la sociedad mexicana ha marcado para la mujer, con su papel público y privado, y con su identidad como actor social. En el mismo sentido, es pertinente la reflexión sobre si esa orientación ha influido en las formas asumidas por las políticas de asistencia social, en su carácter marginal o segregado de las otras políticas sociales, en su ejercicio discrecional, en su fuerza y en su debilidad. En ese marco, se plantea la posibilidad de revisar el papel que las mujeres, representadas en la figura de la

${ }^{11}$ Era tal el estado de pobreza, que periódicos como La Libertad, El Siglo Diecinueve, y La Ilustración Católica, difundían opiniones parecidas: “[...] hoy no caben los enfermos en los hospitales, ni en las casas de beneficencia los pobres, y los fondos públicos no bastan para aliviar a los innumerables que llaman a las puertas de la caridad pública" (La Libertad, 4 de enero de 1874) (Padilla, 1995:25). 
primera dama, han desarrollado en la asistencia pública en México.

Las primeras damas: pasos en la configuración de un ámbito asistencial intermedio entre lo privado y lo público

La imagen de las primeras damas se encuentra, casi siempre, rodeada de un cierto halo mítico, cuya luz deriva, entre otros factores, de una supuesta influencia o vinculación con los espacios de poder; fuerza invisible que frecuentemente ubica a las mujeres como un poder detrás del poder. Muchos de los nombres de estas mujeres asociados a una figura presidencial, han pasado a la historia, bien por su vinculación con las causas sociales, por su personalidad glamorosa o, en otro caso, por haberse constituido, en una determinada época, en prototipos de la identidad femenina. Este apartado busca examinar algunos aspectos de las nociones de lo público y lo privado en el rubro de la asistencia social, relacionados con la influencia y participación de las primeras damas de México en los programas asistenciales; programas que tradicionalmente se han asumido como la responsabilidad de protección a la institución familiar, que cumple la primera dama del país.

Puede decirse que aun cuando la historia registra, antes de 1940, la participación de algunas esposas de los presidentes de México en funciones oficiales de tipo asistencial, éstas se ejercían a título de interés personal. Esto quiere decir que las tareas de beneficencia y caridad que desempeñaron, dependieron de su decisión personal o respondían a propósitos religiosos, de prestigio social y/o a motivaciones de socialización, ubicándose en un ámbito mayormente privado. Es hasta la posguerra que las acciones asistenciales de estas damas adquieren un cierto tono oficial, político: "En adelante se convertirían en madres de todos los desvalidos, protectoras nacionales de la niñez, la mujer, el anciano, el invalido, el artesano. Cuidadoras de la familia, vigilantes de la moral, impulsoras de la cultura. Ahora los decretos presidenciales las nombran, el Estado las patrocina, su práctica se ha institucionalizado en el marco de la politica gubernamental" (Sefchovich, 1982:10). Desde esta posición se supone comúnmente, que ejer- 
cen considerable influencia en la orientación de las estrategias asistenciales. $^{12}$

Al valorar la influencia de estas figuras en la historia de la asistencia social mexicana, es conveniente tener presente que la posición desde la cual ejercieron su función permitía que las instituciones y acciones bajo su control manejaran considerables recursos públicos, encontrándose también en una situación privilegiada para concertar, en torno a sus objetivos particulares, los esfuerzos oficiales y privados. Desde esa óptica se examina aquí su contribución en el devenir histórico de la asistencia, a su conformación como un sector intermedio entre lo público y lo privado. Por una parte, dieron sustento a modos particulares de organización de las políticas públicas asistenciales. En otro sentido, mantuvieron espacios de discrecionalidad y accesibilidad de la asistencia más compatibles con la asunción de lo privado que con los servicios de carácter público. La reflexión sobre la asistencia se orienta por la idea de que la ubicación de las políticas públicas asistenciales en el ámbito de influencia de la primera dama ha sido relevante en las formas asumidas por estas políticas.

Un ejemplo de esa influencia puede apreciarse en que es hasta 1977 que el cargo de presidente del Patronato del Sistema Nacional para el Desarrollo Integral de la Familia, tradicionalmente desempeñado por las primeras damas, adquiere definidamente un carácter institucional, con responsabilidades públicas reglamentadas oficialmente. ${ }^{13}$ Si se tiene en cuenta que este organismo es la institución legalmente facultada para normar y operar la asistencia social en México, ${ }^{14}$ se puede vislumbrar cómo la

${ }^{12}$ Al valorar la importancia de esa participación que se mantiene, con diversos matices, desde principios de siglo, no se debe perder de vista que, como lo señala Grindle, el lugar desde el cual se genera una política ejerce considerable influencia en la viabilidad de su instrumentación (Grindle, 1980).

${ }^{13}$ Cabe aclarar que la reglamentación no prescribe que sea la primera dama quien desempeñe esas funciones, pero que así ha sido desde la fundación de la Asociación Nacional de Protección a la Infancia en 1929, hasta la fecha.

${ }^{14}$ El decreto presidencial de 1977 establece al Patronato como la máxima autoridad del Sistema, e integra a los titulares de algunas de las secretarías de Estado como vocales. Este contexto otorgaba a la esposa del presidente (tradicionalmente, presidenta del Patronato), amplia oportunidad de apoyar sus programas (Diario Oficial de la Federación, 13 de enero de 1977).

En 1982, algunas de las facultades del Patronato fueron transferidas a la Junta de Gobierno presidida por el secretario de Salubridad y Asistencia, dando un carácter más institucional a los programas asistenciales. Éstos fueron jurídicamente sustentados en 1986, con la Ley sobre el Sistema Nacional de Asistencia Social. La esposa del presidente continúa presidiendo el Patronato del DIF. 
ubicación de la política tiene repercusión en su definición pública. La vinculación de la asistencia pública y de algunos sectores asistenciales privados a la imagen de la primera dama, se constituye así en la fortaleza y la debilidad del sistema asistencial.

De la influencia configurada en la participación de la esposa del presidente, de apoyar o restringir la política asistencial; de sus repercusiones en la imagen y legitimación del Gobierno; y del manejo clientelar o institucional de los recursos destinados al combate a la pobreza, se desprende la posibilidad de analizar algunos de los aspectos del desarrollo de la asistencia en México, por medio del papel que han desempeñado las primeras damas.

\section{Personalidades distinguidas, mujeres altruistas y servidoras públicas}

El final del siglo XIX en México, en el terreno asistencial, está marcado entre otros aspectos por la separación del Estado y la Iglesia, que fue gradualmente abriendo espacios a la conformación de un nuevo sentido de lo público, como aquel en el que la sociedad mexicana aceptaba, no sin reticencias, la intervención limitada del Estado en algunos asuntos que se consideraban de interés general. Se puede decir que hacia el final de la Reforma, lo público tendía a configurarse más como el entorno en el que se señalaban límites a la injerencia de la Iglesia, que como el ámbito de competencia propiamente del Estado, mientras lo privado se iba ubicando como la esfera del ejercicio pleno de las libertades individuales, entre ellas la religiosa. El reconocimiento de ámbitos propios de lo privado y de lo público condujo, paulatinamente, al señalamiento de algunas responsabilidades asistenciales para el Estado y para los particulares.

Esta serie de transformaciones resulta más clara si se tiene presente que el liberalismo mexicano pugnaba por las libertades individuales en su sentido absoluto, y que el individuo era de alguna forma el eje rector de los movimientos que buscaban fortalecer al Estado, por lo que el orden social que se proponía alcanzar el Gobierno, no era un orden estricto, y menos aún injerencista, en lo que se consideraba privado. En ese contexto, la responsabilidad de los ricos ante la pobreza era considerada muchas veces solamente una responsabilidad moral, en uso de la cual ellos podían ayudar a los pobres. El Estado no debía intervenir en la administración de la riqueza de los particulares, y menos 
aún en lo concerniente a la propiedad privada; ambas debían protegerse como instrumentos de progreso social (Zea, 1943:18).

Esa concepción se asocia también con el largo proceso de secularización de la vida social y con los cambios en las ideas sobre la moral y el derecho, pues mientras este último debía regir los asuntos de la vida pública, la moral normaba la esfera de la conciencia individual. Para ilustrar esta percepción puede recurrirse a la distinción que hace José María Luis Mora entre la moral privada y la pública, distinguiendo pecado y delito: el primero como asunto de la conciencia individual; el segundo, como asunto de la sociedad (Véase, Padilla, 1995).

Las percepciones sobre la moralidad iban en consonancia con las actividades que hacia el final del siglo pasado se consideraban propias de la mujer, entre las que se cuenta la filantropía. En ella participaron señoras y señoritas que a lo largo de la Reforma y del porfirismo se ocuparon de fundar instituciones de beneficencia, clubes maternales, asociaciones religiosas y sociedades protectoras de la niñez; instancias que a principios del siglo XX asumían una buena parte de la beneficencia (Ramos, 1987). Esas agrupaciones eran impulsadas en buena medida por las damas de la aristocracia social y política.

\section{Asistencia pública y filantropía privada}

Sin duda, el presidente Juárez es uno de los prototipos del pensamiento liberal, que dio impulso y forma a la asistencia social como responsabilidad del Estado mexicano. El decreto de secularización de establecimientos de beneficencia en 1861, colocó a las instituciones asistenciales bajo la responsabilidad de la autoridad pública, y en ese mismo año Juárez estableció la Lotería Nacional, que debía destinar parte de sus ingresos a la beneficencia. Con estas acciones el Estado juarista contribuyó a marcar distinciones de lo público como lo opuesto al poder de la Iglesia y de la religión. Al lado del presidente Juárez, pero prácticamente recluida en el ámbito doméstico y el del cuidado de sus hijos, destaca por su sobriedad la figura de doña Margarita Maza de Juárez. Durante la presidencia de Juárez, ella encabezó una junta de señoras encargadas de reunir fondos para los hospitales de sangre, labor en la que le ayudaron sus hijos; de ella se dijo que: "[...] apenas conoció a los ministros [...] pero estuvo siempre cerca de los pobres y afligidos." (Sefchovich, 1982:20). Su modes- 
tia, su sobriedad, su dedicación al hogar, encarnan de algún modo el modelo de la mujer para una sociedad en la que era generalmente aceptado que el círculo familiar fuese algo apartado de la arena pública, y el hogar considerado una extensión de la propiedad del marido, siendo por tanto inviolable en su privacidad. ${ }^{15}$ En ese tenor la participación asistencial de las mujeres reflejaba, en el modelo de doña Margarita Maza, la caridad asociada a la virtud y como extensión del hogar.

Los cambios en las percepciones de lo privado y de lo público, al finalizar el siglo XIx, se generan insertos en los movimientos de una sociedad que se debatía entre los afanes de progreso y prosperidad de una minoría rica, educada y exigua, en contraste con la pobreza extendida y apabullante que prevalecía en la nación mexicana. Durante el Porfiriato, México vive una intensa modernización industrial; se desarrollan los transportes, las comunicaciones y la economía, y arriba al país una fuerte inversión extranjera; pero es ésta una prosperidad que florece en medio de una pobreza lacerante y de abismales desigualdades: hacia 1878 la población se calculaba en menos de diez millones; 38 por ciento hablaba sólo lenguas indígenas; siete millones de mexicanos eran el México rural; 80 por ciento de los mexicanos habitaban en chozas escuetas, semidesnudos, mal alimentados, en condiciones de servidumbre (Campos, 1995:110).

En esta sociedad desigual, es posible advertir diferencias en la forma como los grupos planteaban y resolvían la asistencia entre la época juarista y el Porfiriato. Mientras en la primera la caridad y la beneficencia privada y pública, la Iglesia y el Estado, se confinaban en ámbitos forzadamente separados, durante el Porfiriato, al aligerarse las tensiones entre la esfera pública y la religiosa, se presenta una sutil ampliación del ámbito privado de la beneficencia y su centro de acción se desplaza hacia la aristocracia y las elites políticas, transitando hacia espacios más abiertos del terreno social.

En ese marco, un papel de primera dama desempeñado con mayor visibilidad correspondió a doña Carmen Romero Rubio de Díaz, quien además de encarnar y regir a la aristocracia social y política, ejerció influencia en una nueva perspectiva de la asistencia. En las elites políticas y sociales porfiristas, la idea de la asistencia era la idea de algo que se podía identificar con la gene-

${ }^{15}$ Benn y Gaus refieren esta percepción del círculo familiar como uno de los rasgos en la concepción liberal, determinante de las distinciones iniciales entre lo público y lo privado (Benn y Gaus, 1983:38). 
rosidad, la filantropía y las buenas intenciones; pero algo finalmente considerado trivial, porque sus alcances no iban más allá de brindar el alivio momentáneo para unos pocos, de los males de la pobreza. Entonces, la caridad seguía el ritmo de los eventos de moda: funciones benéficas de teatro, circo, títeres, verbenas y kermesses, constituían la oportunidad de recaudar fondos para atender a los pobres. ${ }^{16}$ La difusión y elogios que se daban a estas tareas como generosas y humanitarias, dejan translucir cómo, con reconocimientos de este tipo, la sociedad manifestaba su preferencia por las acciones benéficas y su temor por las exigencias y la imposición de obligaciones para con los pobres, haciendo patente la desconfianza que inspiraba la invasión de lo público hacia lo privado. Doña Carmen, como lo consigna González Navarro, en sus ratos libres se dedicó a la beneficencia, estableciendo la "Casa de la Amiga Obrera", la cual tenía entre sus finalidades la enseñanza, guarda y atención de los hijos de las obreras (González Navarro, 1985).

Una medida que impulsó la participación de las asociaciones privadas en la asistencia, fue tomada por el presidente Díaz al decretar la constitución de la Junta de Beneficencia Privada, organismo al que se encomendó la promoción y vigilancia de los establecimientos fundados por particulares. La creación de este marco de derecho y reconocimiento para los particulares, propició que contaran con mayores recursos, y se tradujo en mayor visibilidad y amplitud de las acciones filantrópicas. Esta decisión estableció en esferas jurídicas reconocidas como separadas, la asistencia pública y la privada, propiciando el desarrollo de intencionalidades, modos de organización y criterios de accesibilidad distintos, los cuales estuvieron asociados con la libertad de los particulares para realizarla.

La mayor participación de las señoras en la asistencia en este periodo, no era quizás ajena a las ideas sobre el progreso. Las damas que se hacían llamar de la asociación "Caridad y Progreso", por ejemplo, implicaban la percepción de que para alcanzar la modernidad que pregonaba el régimen era indispensable ejercer la caridad. Posiciones como ésta no se reflejaron necesariamente en avances en los programas sociales, pero pudieron

${ }^{16}$ Una de las pocas actividades que se consideraban propias de la mujer de alta sociedad es la filantropía, en la que participan señoras y señoritas que se ocupan de fundar instituciones de beneficencia (Ramos, 1987). En el mismo sentido se insertan los clubes maternales, las sociedades de orientación protestante y la sociedad protectora de la niñez, que a principios de siglo asumen buena parte de la beneficencia. 
haber contribuido en la modificación de actitudes hacia los problemas de la pobreza y repercutido en la reorganización de la beneficencia privada, permitiendo al mismo tiempo a las mujeres apropiarse de la escena de la asistencia como un espacio de socialización. Las reuniones, veladas y funciones, al tiempo que recaudaban fondos para la beneficencia, permitían a las mujeres circular marginalmente por los espacios públicos e impulsar la conciencia de género y de derechos sociales y ciudadanos para las mujeres.

La Revolución cambió radicalmente este panorama, abriendo nuevos escenarios y colocando nuevos actores en la discusión de las responsabilidades sociales. Las demandas de justicia social y de igualdad que movieron los levantamientos armados se constituyeron en fuertes corrientes de oposición a la visión individualista del Porfiriato, fortaleciendo en la Carta Magna de 1917, la idea de un Estado activo, e incluso interventor, en la consecución del bienestar general. En medio del despertar de esa nueva conciencia, hubo cambios significativos en la concepción de lo público y de lo privado en el rubro asistencial. La asistencia adquirió, como rasgos intrínsecos, el de ser pública y de interés social, entendidos como la facultad del Estado de ordenarla, promoverla y ejecutarla, estableciendo incluso orientaciones normativas para los particulares. La asistencia es identificada entonces con la noción de universalidad de los derechos sociales, abarcando la educación, la salud, la vivienda y el vestido. La amplitud de la acción estatal y su carácter incluso coercitivo, se encaminaban a asegurar beneficios irrenunciables para toda la población.

La propia lucha armada, las asonadas y la inestabilidad política, no permitieron que las primeras damas del periodo posrevolucionario adquirieran notoriedad en sus funciones oficiales, las que tuvieron lugar generalmente fuera del protocolo y de la luz pública. Igualmente, la guerra alejó a las mujeres de las instituciones asistenciales; solamente las mujeres de las clases bajas, "las soldaderas", acompañaban y consolaban a los combatientes; ellas eran también encarnación del dolor y la pobreza. En este difícil panorama las fronteras entre lo público y lo privado, para las mujeres, se diluyen. 


\section{Asistencia social}

Al pacificarse el país y asumir carácter institucional, como responsabilidades estatales, algunas de las causas revolucionarias, el papel de las mujeres en la asistencia empieza a transformarse. Doña Carmen García de Portes Gil es ejemplo de este nuevo paradigma de la mujer. No solamente se presentó con frecuencia en actos y ceremonias oficiales, sino que además:

[...] desarrolló una intensa actividad, que sentó las bases de lo que en adelante sería la función de las primeras damas en nuestro país. Durante dos años trabajó para los niños y las madres, y centralizó la asistencia social. En 1929 creó y presidió la Asociación Nacional de Protección a la Infancia, con oficinas en el propio Castillo de Chapultepec; repartió desayunos y fundó las primeras escuelas-hogar, sitios en los que las mujeres podían dejar a sus hijos en cuidado mientras salían a trabajar. Estableció centros para mujeres en estado de gravidez, de los cuales hubo delegaciones en casi todas las capitales de los estados. Fundó "La Gota de Leche”, asociación que obsequiaba ese importante alimento a los niños humildes. Inauguró escuelas y casas de salud cuyo principal objetivo consistió en combatir la alta mortalidad infantil (Sefchovich, 1982:36).

"Para sostener ese trabajo, doña Carmen recibió donativos y mandó imprimir un timbre postal con cuya venta se recaudaron más de cinco millones de pesos (de aquellos), los que se destinaron a la construcción de centros de higiene infantil" (Sefchovich, 1982:36-40). Resulta interesante apreciar en este recuento, cómo la Asociación Nacional de Protección a la Infancia y las asociaciones y tareas asistenciales que se reseñan, se articulan como acciones intermedias entre lo público estatal y lo privado como responsabilidad de la sociedad civil, porque a más de recibir fondos públicos, se presenta una institucionalidad incipiente con acciones de carácter y administración privadas.

Las medidas de protección social emprendidas por el presidente Cárdenas (1934-1940), constituyeron un cambio radical en la perspectiva de cómo debía la sociedad mexicana enfrentar las necesidades sociales, y se incorporó un nuevo concepto, la asistencia social. A partir de ese momento, la asistencia pública se estableció como una obligación política del Estado hacia la sociedad en general, la cual comprendía la subsistencia y el tratamiento médico de los socialmente débiles; esta asistencia se esforzaría por hacer útiles a estas personas para la colectividad y buscaría 
extender sus labores a todo el país, además de vigilar la asistencia privada para adecuarla a esta orientación.

Posiblemente es durante el régimen cardenista que la política asistencial adquiere su dimensión más amplia en la concepción de atender a la procuración de derechos sociales para todos los pobres y no solamente para los vulnerables, enfermos, inválidos o abandonados; aproximándose a la idea de que todo ser humano tiene derecho a que se le asista cuando carece de los medios necesarios para vivir, noción cercana a la de mínimos de bienestar para la población, que incluía también la prevención de la debilidad económica y social. En términos del presidente Cárdenas: "[...] sólo de este modo, contribuye la asistencia pública a ampliar las bases económicas y sociales que necesita la revolución para realizar plenamente su finalidad humanista de mejorar y ennoblecer la vida de su población" (Cárdenas, 1939). Sin embargo, este proyecto fue de corta vigencia, ya que posteriormente el consenso volvería a romperse, denunciándose el intervencionismo del Estado y la necesidad de una mayor participación de la sociedad civil. ${ }^{17}$

La reconstitución de lo público y de lo privado en esta etapa hace visible que en la medida en que la asistencia se institucionaliza y se vuelve de competencia estatal -incluyendo en la noción de lo público el reconocimiento de una clase de bienes públicos a los cuales todos debieran tener acceso-, el papel de las mujeres en la asistencia se transforma; su participación en el trabajo asistencial se vuelve profesional y adquiere también un carácter público. La organización y operación de un sistema asistencial requirió de maestras, enfermeras, secretarias y profesionales diversas que hicieran realidad los propósitos asistenciales. En ese contexto, la figura de la primera dama no alcanzó relevancia; quizás por estas razones la señora Amalia Solórzano de Cárdenas decidió no participar públicamente en ese carácter.

\section{Asistencia pública selectiva y asistencia privada}

El renacimiento del debate sobre la posición del Estado mexicano ante la pobreza y la reconstitución de lo privado y de lo públi-

${ }^{17}$ La idea del "Estado de Bienestar" como aquel en el cual el Estado es utilizado deliberadamente para modificar las fuerzas del mercado (Kusnir, 1996:35), no se vincula necesariamente con un régimen socialista, ya que en la concepción ideal del Estado socialista, las políticas sociales ya no existirían, por no ser necesarias. 
co hacia la esfera intermedia de lo social, se puede apreciar en lo acontecido con la asistencia en el periodo que va de la presidencia de Ávila Camacho a la de López Mateos (1940-1958), cuando después de la acentuada intervención estatal del cardenismo, hay una retracción del papel del Estado ante el bienestar, misma que se expresa, entre otros aspectos, en la separación de los ámbitos de la salud y la asistencia. Habría un espacio destinado a las acciones de salud; las de asistencia pasan a ser consideradas como de atención a grupos menesterosos, ${ }^{18}$ y en una ampliación de la participación privada.

El replanteamiento de los alcances del papel del Estado en la tarea asistencial, trajo a la discusión pública la temporalidad de la ayuda que el Estado pudiera brindar a las clases desposeídas; no se podían prevenir los males de la pobreza y los recursos públicos eran insuficientes para pensar en apoyos duraderos. La miseria desaparecería porque el desarrollo traería consigo una ampliación de la seguridad social y, en consecuencia, la asistencia no sería necesaria. Estas ideas eran, en alguna medida, un reflejo de las tendencias prevalecientes sobre el desarrollo al principio de la posguerra en el ámbito internacional, que se movían bajo el supuesto de que los frutos del crecimiento podrían automáticamente y dentro de un periodo aceptable de tiempo, extenderse a los sectores menos privilegiados de la economía.

Doña Soledad Orozco de Ávila Camacho recuperó entonces espacios para la filantropía y la asistencia privadas en aspectos no considerados entonces de manera oficial. Así, por ejemplo, institucionalizó el día de las madres haciendo obsequios a las madres humildes, y es de hacer notar el papel mediador que desempeñó en las nuevas relaciones entre el Estado y la Iglesia en México (Sefchovich, 1982). Hacia 1943 destacan también las acciones de las voluntarias, como es el caso de las "voluntarias del Hospital Infantil de México" y de otros grupos que aún tienen vigencia. La denominación "voluntaria" llevaba implícita la connotación "fuera del ámbito estatal", al que se considera coerciti-

${ }^{18}$ La asistencia pública fue considerada en este periodo como un régimen de protección dependiente del poder público, de carácter no contributivo, que cumple la obligación que tiene el Estado de suministrar ayuda a los menesterosos sólo en la medida de sus posibilidades económicas (Gustavo Baz: secretario de Salubridad, 1943). Asimismo, se prescribía que además de circunscribirse a la población menesterosa, la ayuda que concedía era eventual y de naturaleza diversa; ya no se debía prever, sino sólo ayudar, porque de otro modo se contribuiría a perpetuar el desnivel económico de las clases sociales. (Ponencia del Dr. Gaudencio González Garza, en el 1er. Congreso Nacional de Asistencia Social, 1943; y Álvarez Amézquita, 1960). 
vo. La privacidad de las asociaciones voluntarias que desarrollan acciones asistenciales corporativas se estructura entonces en torno a una identidad en la que tales grupos se consideran vehículos por medio de los cuales pueden perseguirse fines particulares y desarrollar modos propios de acción: éstos no son necesariamente lucrativos o egoístas, sino libres de la normatividad de la asistencia pública. La diferente perspectiva de lo público y de lo privado en la atención hacia la pobreza se acota también por la creación de los sistemas de seguridad social, ya que a partir de entonces la asistencia y la seguridad seguirían caminos distintos: la primera vinculada con la pobreza extrema y la vulnerabilidad, y la segunda, con el mundo del capital y el trabajo.

En el mismo sentido se inscribe la participación de doña Beatriz Velasco de Alemán, quien no sólo convoca el apoyo y donativos de las organizaciones privadas en tareas asistenciales, sino que también introduce la ayuda gubernamental para programas y organizaciones privadas, y la de algunos organismos internacionales. Esta posición marca un giro importante al superarse algunas de las mutuas desconfianzas entre el Estado y los particulares, abriendo nuevas vías por las que habían de canalizarse recursos a la asistencia.

El balance de la política social en el rubro asistencial hacia la mitad del siglo xx es el de un esquema de atención selectivo entre la pobreza, con una cobertura restringida de beneficios (centrada fundamentalmente en la salud y alimentación básicas). Si se toma en cuenta que la seguridad social se afianzó para los obreros, profesores, burócratas y militares, la selectividad de la seguridad social y de la asistencia significó la exclusión de amplios sectores de población que no contaron con ningún tipo de apoyo, especialmente en la zonas indígenas rurales y urbano marginadas. En este contrastante panorama el paradigma de la primera dama convocante de acciones estatales y privadas adquirió su mayor relevancia.

Se podría afirmar que es con doña Eva Sámano de López Mateos que esta figura adquiere una dimensión nacional, pues se inicia la coordinación de institutos y centros regionales de asistencia en toda la República, y las esposas de los gobernadores estatales se integran en una red de apoyo a los programas asistenciales. Es decir, la imagen de la primera dama se reproduce en el espacio de los estados y de los municipios. A pesar de la expansión de algunos programas; del establecimiento del Instituto $\mathrm{Na}$ cional de Protección a la Infancia, que dio carácter público, ofi- 
cial, a la asistencia; y de la amplia difusión que se otorgaba a las acciones presidenciales, incluidas las de las damas, la política asistencial tomaba, cada vez más, un lugar secundario en los proyectos mediante los cuales se pretendía resolver los problemas del país.

El periodo comprendido entre la administración de Díaz Ordaz y el gobierno de José López Portillo, fue una etapa de gran participación de las damas en la asistencia y en la cultura, diversificándose los proyectos con los que se esperaba resolver las necesidades de la pobreza, que ya no se veían tan urgentes ante las expectativas del desarrollo económico. Numerosos testimonios registran la intensa actividad de doña María Esther Zuno y de doña Carmen Romano; mientras, en términos concretos, la asistencia venía reduciendo sus alcances, condicionando sus apoyos y reduciendo selectivamente su población objetivo.

La reducción y fragmentación del campo asistencial en las esferas pública y privada pueden constatarse en las formas como la señora Echeverría propuso el tratamiento unitario de lo que consideró tres conceptos fundamentales: niño, familia y comunidad; amplió además las funciones de las instituciones asistenciales a la formación educativa y cultural extraescolar, la recreación y la promoción del desarrollo de la comunidad (DIF, 1976). En esta nueva perspectiva el lenguaje de la asistencia adoptó el énfasis de la promoción del desarrollo de las zonas marginadas. Doña María Esther impulsó también la constitución de grupos voluntarios incentivados por las esposas de los funcionarios públicos, a los que se encomendaba actividades de promoción social, entendida ésta como "[...] un mecanismo para que la gente menos favorecida desarrollara sus propias potencialidades". ${ }^{19}$ Por su parte, la señora López Portillo acentuó la diversificación de las tareas asistenciales estableciendo 42 líneas diferentes de acción para el Patronato de Promotores Voluntarios, privilegiando la difusión cultural como parte de la extensión de la asistencia. La creación del Fondo Nacional para la Asistencia (FONAPAS), promotor de actividades artísticas y culturales como parte de las acciones asistenciales, es un buen ejemplo de la poca especificidad en la concepción asistencial. Estos modos de entender y operar la asistencia demandaron la constitución de grupos de mujeres, servidoras

${ }^{19}$ En conceptos como éstos se puede advertir, entre otros muchos, el cambio que en lo asistencial se había dado, de un Estado responsable de asegurar derechos para todos, a uno que solamente incentivaría los esfuerzos de los grupos menos favorecidos (PNPV, 1994). 
públicas o voluntarias, con mayor presencia pública y ejecutiva. La imagen de mujer altruista había sido sustituida por la de la mujer ejecutiva, de la que se esperaba la apertura de nuevos espacios para que los recursos para la asistencia pudiesen fluir por vías distintas a las estatales.

\section{Solidaridad social}

El final de los años setenta significó, en buena medida, la conclusión del modelo asistencial centrado en la responsabilidad estatal: la reducción, fragmentación y pérdida de importancia gradual de la acción asistencial, pueden interpretarse como parte del inicio de la configuración estructural del modelo de economía neoliberal, que se caracteriza por minimizar la intervención estatal en la economía y por un desmantelamiento del sector público, en una tendencia hacia "la sustitución del Estado por el mercado”. En este esquema, la política asistencial asumió, cada vez más, una orientación compensatoria de las medidas de ajuste macroeconómico. Una nueva reconstitución de las nociones de lo público y lo privado en la asistencia tomó forma con las demandas y planteamientos de que las políticas públicas asistenciales no tendrían que provenir solamente del Gobierno, sino también de las organizaciones de la sociedad y de los propios beneficiarios. Esta corriente fue además impulsada por los afanes de movilización de la sociedad mexicana, que veía estrechos los canales burocráticos.

El sentido moderno de la asistencia social atribuido a los grupos voluntarios organizados en el Patronato de Promotores Voluntarios, durante la presidencia de la señora Ocelli de Salinas, radicó en buena medida en la idea de que las acciones fuesen definidas por las necesidades de los propios demandantes. La acción voluntaria asistencial estuvo concebida como un proceso de corresponsabilidad, tendiente a la mayor autonomía y gestión de los grupos comunitarios (PNPV, 1994). ${ }^{20}$ Lo privado en el terreno de la asistencia pudo entonces tener una significativa expansión en el campo considerado antes de responsabilidad estatal.

${ }^{20} \mathrm{El}$ enfoque de la labor social se consideró sustentado en tres principios básicos: la capacitación, la organización para el trabajo productivo y la corresponsabilidad de los beneficiarios (PNPV, 1994). 
En México, en los últimos años se han multiplicado las organizaciones sociales y privadas que brindan apoyo a la población más necesitada. En todas ellas un gran número de personas, en su mayoría mujeres, destinan tiempo y trabajo a la asistencia. La función de la primera dama en el terreno asistencial dejó hace ya tiempo de tener impacto y repercusión nacionales en la atención a los problemas de la pobreza. Al margen del destino poco esperanzador de éstas y otras políticas que combaten la pobreza, quizás es tiempo de replantear también el papel de las primeras damas en el campo asistencial.

\section{Reflexiones finales}

Con esta breve revisión se ha tratado de identificar la presencia de la mujer en los movimientos y cambios de la asistencia social en México. A pesar de que la información manejada en estas notas es muy limitada, aporta indicios del papel relevante de las mujeres como actores de la asistencia social; asimismo, esboza algunos de los diversos ángulos desde los cuales podría abordarse este estudio y de la riqueza que podría encontrarse en una indagación de mayor amplitud y profundidad sobre el tema.

En esa reflexión destaca la importancia de las nociones de lo público y de lo privado como elementos constitutivos de las ideas que sobre la asistencia se comparten en una sociedad, haciendo perceptible la pluralidad desde la cual pudiera abordarse su estudio, y advirtiendo nuevas perspectivas para el análisis de las políticas sociales.

Sin que este breve análisis pretenda arribar a conclusiones, no se debe dejar de notar la aparente falta de coherencia en el hecho de que la mayor participación de las primeras damas como protagonistas de la acción asistencial coincida con los momentos en que las políticas asistenciales han sufrido, de modo general, mayores retracciones. Esta percepción, al margen de poder ser resultado de diversas causalidades, no deja de aislar e impregnar con cierto matiz de irrelevancia la labor de las primeras damas; lo cual no significa, de ninguna manera, que las acciones sociales emprendidas por ellas no fuesen benéficas y necesarias en un país de extendida pobreza, sino que los programas asistenciales y las dimensiones reales de atención a la pobreza, están regidos por otros designios, que no pasan por la influencia posible de la primera dama. En el mismo sentido se apunta que la identificación 
de las acciones de las primeras damas como tareas asistencialistas y ejercidas en el contexto de un espíritu altruista -al margen de la política-, pudo haber contribuido a la ubicación ambigua de la política pública asistencial como un asunto no político y obstaculizado su viabilidad.

Bajo esas premisas, es posible pensar que los programas desarrollados en torno a las primeras damas y el propio papel cumplido por ellas, estuviesen más influidos por factores asociados con motivaciones de carácter político-social y con valores culturales, que con las necesidades reales de la población extremadamente pobre, y que en esta concepción tuvieran algún peso los valores que se relacionan con la configuración de lo público y de lo privado, asociados con la identidad de la mujer en los distintos tiempos de la modernidad.

\section{Bibliografía}

Álvarez Amézquita, José (1960), Historia de la salubridad y de la asistencia en México, vol. III, México, Secretaría de Salubridad y Asistencia.

Benn, Stanley y Gerald F. Gaus (1983), “The Liberal Conception of the Public and the Private", en Public and Private in Social Life, Londres y Canberra, Croom Helm.

Campos, Julieta (1995), ¿Qué hacemos con los pobres?; la reiterada querella por la nación, México, Editorial Aguilar-Altea-Taurus-Alfaguara.

Cohen, Sean L. y Andrew Arato (1996), Civil Society and Political Theory, Boston, Mit Press.

De Giorgio, Michela (1993), “El modelo católico”, en Duby Georges y Michelle Perrot (eds.), Historia de las mujeres en Occidente, tomo 4, Madrid, Taurus Ediciones, pp. 183218.

De Gortari, Hira y Alicia Ziccardi (1996), "Instituciones y clientelas de la política social: un esbozo histórico, 1867-1994”, en Las políticas sociales de México en los años noventa, México, Instituto José María Luis Mora-Universidad Na- 
cional Autónoma de México-Facultad Latinoamericana de Ciencias Sociales-Editorial Plaza y Valdés, pp. 201-234.

DIF (1976), El proceso de cambio y tendencias generales de politica social en el Instituto Mexicano para la Infancia y la Familia, 1970-1976, México, Sistema para el Desarrollo Integral de la Familia.

Elshtain, Jean Bethke (1981), Public Man, Private Woman; Women in Social and Political Thoght, Nueva Jersey, Princeton University Press.

González Navarro, Moisés (1957), "El porfiriato: la vida social”, en Daniel Cossío Villegas, Historia moderna de México, vol. Iv, México, Editorial Hermes.

— (1985), La pobreza en México, México, El Colegio de México.

Grindle, Merilee S. (1980), Politics and Policy Implementation in the Third World, Nueva Jersey, Princeton University Press.

Habermas, Jurgën (1997), “The Public Sphere”, en Contemporary Political Philosophy. An Anthology, Blackwell Publishers Ltd., Oxford, 1ª ed. 1989.

Kymlicka, Will (1990), Contemporary Political Philosophy. An Introduction, Nueva York, Oxford University Press.

Knibiebler, Yvonne (1993), “Cuerpos y corazones”, en Duby Georges y Michelle Perrot (eds.), Historia de las mujeres en Occidente, tomo 4, Madrid, Taurus Ediciones, pp. 321368.

Koselleck, Reihart (1993), Futuro. Pasado: para una semántica de los tiempos históricos, Barcelona, Ediciones Paidós.

Kusnir, Liliana (1996), La política social en Europa, México, Miguel Angel Porrúa. 
Lefaucher, Nadine (1993), "Las grandes mutaciones del siglo: maternidad, familia, Estado", en Duby Georges y Michelle Perrot (eds.), Historia de las mujeres en Occidente, tomo 4, Madrid, Taurus Ediciones, pp. 439-463.

Luckmann, Thomas (1973), La religión invisible, Salamanca, Ediciones Sígueme.

Miranda Pelayo, Jorge (1988), Temas de asistencia social, SNDIF (mimeo).

Olmedo Carranza, Raúl (1987), “El DIF y la descentralización”, en INAP-DIF, La administración municipal y el sistema para el desarrollo integral de la familia, México, INAP-DIF.

Oszlak, Óscar (1980), Politicas públicas y regímenes politicos: reflexiones a partir de algunas experiencias latinoamericanas, Documento CEDES, vol. 3, núm. 2, Buenos Aires, Centro de Estudios de Estado y Sociedad.

Padilla Arroyo, Antonio (1995), Criminalidad, cárceles y sistema penitenciario en México, 1876-1910, tesis del doctorado en historia, México, El Colegio de México.

Patronato Nacional de Promotores Voluntarios (1994), La acción voluntaria en el contexto histórico de la asistencia social en México, México, Editorial Gustavo Casasola.

Perrot, Michelle (1993), "Salir", en Duby Georges y Michelle Perrot (eds.), Historia de las mujeres en Occidente, tomo 4, Madrid, Taurus Ediciones, pp. 461-496.

Ramos Escandón, Carmen (1987), "Señoritas porfirianas: mujer e ideología en el México progresista, 1880-1910”, en Presencia y transparencia: la mujer en la historia de México, México, El Colegio de México.

Rawls, John (1971), A Theory of Justice, Gran Bretaña, Cambridge, Mass.

- (1995), Liberalismo político, México, Universidad Nacional Autónoma de México-Fondo de Cultura Económica. 
Sefchovich, Sara (1982), Las primeras damas. II. Memoria y olvido: imágenes de México, México, Martín Casillas Editores-Cultura SEP.

Seligman, B. Adam (1996), The Idea of Civil Society, Gran Bretaña, Princeton Press.

Sievers, Bruce (1995), Can Philantropy Solve the Problems of Civil Society?, Indianapolis, Indiana University Center on Philantropy.

Soberón Acevedo, Guillermo y Cuauhtémoc Valdés Olmedo (1988), "El sistema nacional de salud, marco de referencia para la asistencia social (orígenes, definiciones, avances)", en Asistencia social: estrategia de solidaridad nacional, evolución y desarrollo, México, SNDIF.

Thebaud, Fraçoise (1993), “Introducción”, en Duby Georges y Michelle Perrot (eds.), Historia de las mujeres en Occidente, tomo 4, Madrid, Taurus Ediciones.

Walzer, Michael (1993), Las esferas de la justicia: Una defensa del pluralismo y la igualdad, México, Fondo de Cultura Económica.

Zea, Leopoldo (1985), El positivismo y la circunstancia mexicana, México, Fondo de Cultura Económica-SEP, 1ª ed. 1943.

\section{Documentos}

Diario Oficial de la Federación (1986), Ley sobre el Sistema Nacional de Asistencia Social, 9 de enero.

DIF-FONAPAS (1982), Memoria Sexenal, 1977-1992, Sistema para el Desarrollo Integral de la Familia.

Poder Ejecutivo (1939), Lázaro Cárdenas, Informe de Gobierno. 
